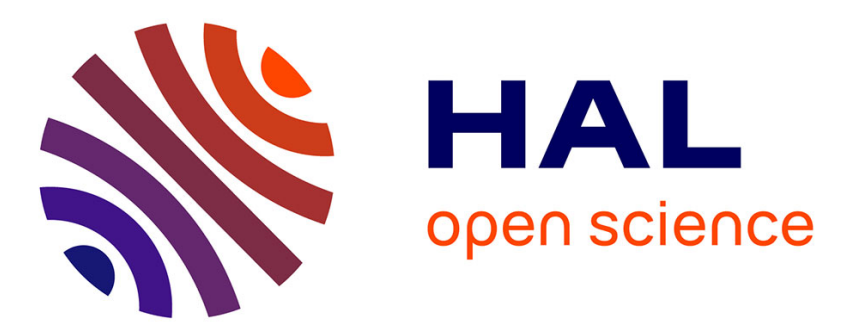

\title{
PBPK modelling of inter-individual variability in the pharmacokinetics of environmental chemicals
}

Frédéric Y. Bois, Massoud Jamei, Harvey J. Clewell

\section{To cite this version:}

Frédéric Y. Bois, Massoud Jamei, Harvey J. Clewell. PBPK modelling of inter-individual variability in the pharmacokinetics of environmental chemicals. Toxicology, 2010, 278 (3), pp.256-267. 10.1016/j.tox.2010.06.007 . ineris-00961755

HAL Id: ineris-00961755

https://hal-ineris.archives-ouvertes.fr/ineris-00961755

Submitted on 20 Mar 2014

HAL is a multi-disciplinary open access archive for the deposit and dissemination of scientific research documents, whether they are published or not. The documents may come from teaching and research institutions in France or abroad, or from public or private research centers.
L'archive ouverte pluridisciplinaire HAL, est destinée au dépôt et à la diffusion de documents scientifiques de niveau recherche, publiés ou non, émanant des établissements d'enseignement et de recherche français ou étrangers, des laboratoires publics ou privés. 


\title{
PBPK MODELLING OF INTER-INDIVIDUAL VARIABILITY IN THE PHARMACOKINETICS OF ENVIRONMENTAL CHEMICALS
}

\author{
Frédéric Y. Bois ${ }^{a, b}$, Masoud Jamei ${ }^{c}$, Harvey J. Clewell ${ }^{d}$
}

a UTC, Technological University of Compiegne, Chair of Mathematical Modelling for Systems Toxicology, Royallieu Research Centre, BP 20529, 60205 Compiegne Cedex, France (Frederic.Bois@utc.fr)

b INERIS, Parc Technologique ALATA, BP2, 60550 Verneuil en Halatte, France

c Simcyp Limited, Blades Enterprise Centre, John Street, Sheffield, S2 4SU, United Kingdom (M.Jamei@simcyp.com)

d The Hamner Institutes for Health Sciences, 6 Davis Drive, Research Triangle Park, North Carolina, 27709, USA (HClewell@thehamner.org)

\section{Corresponding author}

Frédéric Yves Bois

INERIS

Parc ALATA, BP2

60550 Verneuil en Halatte

France

Phone: +33 344556596

Fax: +33 344556175

Frederic.Bois@ineris.fr

\section{Abbreviations}

$A A G: \quad \alpha_{1}$-acid glycoprotein

$A B C B 1: \quad$ Adenosine triphosphate binding cassette member B1

ABCC2: $\quad$ Adenosine triphosphate binding cassette member $\mathrm{C} 2$

ABCG2: $\quad$ Adenosine triphosphate binding cassette member G2

ACAT model: Advanced Compartmental Absorption and Transit model

ADAM model: Advanced Dissolution, Absorption and Metabolism model

ADME: $\quad$ Absorption, distribution, metabolism, excretion

$A U C: \quad$ Area under the curve 
BCRP: $\quad$ Breast cancer resistance protein

CAT model: Compartmental Absorption and Transit model

CYP: $\quad$ Cytochrome P450

GFR: $\quad$ Glomerular filtration rate

HPGL: Hepatocellularity

IPA: Isopropanol

MCMC: $\quad$ Markov Chain Monte Carlo

MDR1: $\quad$ Multi-drug resistance protein

MRP2: $\quad$ Multidrug-resistance protein 2

PBPK: $\quad$ Physiologically Based Pharmacokinetic Model

$P-g p: \quad$ P-glycoprotein 


\section{ABSTRACT}

Generic PBPK models, applicable to a large number of substances, coupled to parameter databases and QSAR modules, are now available for predictive modelling of inter-individual variability in the absorption, distribution, metabolism and excretion of environmental chemicals. When needed, Markov chain Monte Carlo methods and multilevel population models can be jointly used for a Bayesian calibration of a PBPK model, to improve our understanding of the determinants of population heterogeneity and differential susceptibility. This article reviews those developments and illustrates them with recent applications to environmentally relevant questions.

\section{KEYWORDS}

Drug-drug interactions, Markov chain Monte Carlo, Monte Carlo simulations, PBPK models, Pharmacokinetics, Population models, Susceptible populations, Toxic interactions, Toxicokinetics, Variably assessment. 


\section{INTRODUCTION}

PBPK models are now commonly used in drug development and regulatory toxicology to predict the kinetics and metabolism of substances in the body, with a focus on the effective dose at the expected target site (Barton et al. 2007; Bouvier d'Yvoire et al. 2007; Edginton et al. 2008; Loizou et al. 2008).

The physiological basis of PBPK models makes them especially suited to explore, understand and predict the determinants of inter- or intra-individual variability in pharmacokinetics. Those translate into variability of target doses and can have direct consequences for therapeutic safety and the likelihood of toxicity, especially for compounds with narrow therapeutic windows or a steep dose-response for toxicity. Therefore, simulation of inter-individual variability has become an integral part of the assessment of pharmacokinetics in humans (Bois 2001; Rostami-Hodjegan and Tucker 2007). The mechanistic framework of PBPK models provides the capacity of predicting inter-individual variability in pharmacokinetics when the required information is adequately incorporated. This short review presents the state of the art on this question and illustrates the approach with two recent applications of the Simcyp software to environmentally relevant questions.

\section{PBPK MODELING}

When a chemical substance penetrates an animal body (following intentional administration or unintentional exposure), it is usually distributed to various tissues and organs by blood flow (Gerlowski and Jain 1983; Nestorov 2007). Following its distribution to tissues, the substance can bind to various proteins and receptors, undergo metabolism, or can be eliminated unchanged. The concentration versus time profiles of the xenobiotic in different tissues, or the amount of metabolites formed, are often used as surrogate markers of its internal dose or biological activity (Andersen 1995). 
Mathematical models can be used to interpolate and extrapolate (predict) such concentrationtime profiles from data. Reported models range from simple compartmental (Gibaldi and Perrier 1982) to very sophisticated (Jamei et al. 2009a; Luecke et al. 2008). PBPK models are evolved compartmental models which tend to use realistic biological descriptions of the determinants that regulate the disposition of drugs in the body (Andersen et al. 2005). Those models describe the body as a set of compartments corresponding to specific organs or tissues (e.g., adipose, bone, brain, gut, heart, kidney, liver, lung, muscle, skin, and spleen, etc.). Between compartments, the transport of substances is dictated by various physiological flows (blood, bile, pulmonary ventilation, etc.) or by diffusion (Bois and Paxman 1992; Gerlowski and Jain 1983). Perfusionrate-limited kinetics applies when the tissue membrane presents no barrier to distribution. Generally, this condition is likely to be met by small lipophilic substances. In contrast, permeability-rate kinetics applies when the distribution of the substance to a tissue is rate-limited by the drug's permeability across the tissue membrane. That condition is more common with polar compounds and large molecular structures. Consequently, the related PBPK models may exhibit different degrees of complexity. In the simplest and most commonly applied form (see Figure 1), each tissue is considered to be a well-stirred compartment in which the substance distribution is simply limited by blood flow. In such a model, any of the tissues can be a site of elimination. However, in Figure 1, it is assumed that the gut, liver and kidney are the only metabolising tissues and that excretion only happens in the kidney.

Building a PBPK model requires gathering a considerable amount of data which can be categorised in three groups: namely, the system's data (physiological, anatomical, biochemical data); drug-specific data; and the model structure, which refers to the arrangement of tissues and organs included in the model (Rowland et al. 2004). In a sense, PBPK modelling is an integrated systems approach to both understanding the pharmacokinetic behaviour of compounds and predicting concentration-time profiles in plasma and tissues. Additional details on PBPK modelling can be found elsewhere (Gerlowski and Jain 1983; Nestorov 2003; Rowland et al. 
2004). Indeed, such a description of the body is approximate, if not rough, but a balance has to be found between precision (which implies complexity) and simplicity (for ease of use). Yet, the generic structure of a PBPK facilitates its application to any mammalian species as long as the related system data are used. Therefore, the same structural model can approximately be used for a human, a rat or a mouse.

The model structure can be described by a set of differential equations, with parameters representing blood flow rates, organ volumes etc., for which information is available in the published scientific literature or may be obtained in vitro (Parrott et al. 2005; Woodruff and Bois 1993). Numerical integration of that differential system computes the quantity and concentration of the drug considered in each compartment, as a function of time and exposure dose.

\section{VARIABILITY VS. UNCERTAINTY}

Inter-individual differences ("variability"), in the anatomical and physiological characteristics of humans or animal are glaring and a common experience. Such differences affect, for example, organ volumes and blood flow and translate quite naturally into variability in the pharmacokinetics of drugs and chemical substances from one individual to the next. Since pharmacokinetics determine, in part, effective dose and ensuing effects, pharmacokinetic variability has an impact on individual susceptibility. Two major, complementary, modelling approaches have been developed to understand, evaluate and predict that variability: A priori and a posteriori modelling.

A priori (bottom-up), purely predictive, modelling of variability can be undertaken either through deterministic descriptions of the determinants of variability or through stochastic simulations (Monte Carlo methods) (Bois et al. 1990; Clewell and Andersen 1996; Clewell et al. 2004; Rostami-Hodjegan and Tucker 2007; Willmann et al. 2009; Willmann et al. 2007). Both approaches can also be combined. Deterministic modelling motivations stem, partly, from the 
fact that some of the differences between individuals are due to growth and other age-related changes, or sex, etc. Such changes can be explicitly modelled in life-time PBPK models (Clewell et al. 2004; Edginton et al. 2006). Monte Carlo methods acknowledge (some may say: hide intellectual laziness behind) the fact that part of the differences between individuals seem to occur by chance or cannot be ascribed simply to easily modelled determinants such as age etc. In that case, those differences are considered as purely random and parameter values are described by statistical distributions, rather than point estimates or simple functions of time, sex or other covariates.

A posteriori (top-down) modelling of inter-individual variability is data-based, and was originally developed in pharmacokinetics, where human data were routinely generated through clinical trials. The aim here is to assess, for example, how across-subject variability of blood concentration for a substance can be explained by variability in renal excretion rate, bioavailability, metabolic rate, etc. That is best achieved through inverse simulation in the framework of multilevel statistical models ("population pharmacokinetic models") (Bois 2001; Sheiner 1984). That approach was first used with classical (minimal) compartmental models (Beal and Sheiner 1980, 1982), but the added ingredients of MCMC simulations and Bayesian inference make it amenable to the treatment of PBPK models (Bois et al. 1996a; Bois et al. 1996b; Gelman et al. 1996). After unrolling the determinants of variability, forward, predictive, simulations can be performed to assess their impact in various exposure and risk or clinical treatment scenarios.

Uncertainty is different from variability, although their effects may be confounded and compounded. Uncertainty is essentially due to lack of knowledge and may have various sources. For example, measurements are made only with finite precision; so when data are used to fit toxicokinetic or toxicodynamic models, there is always some uncertainty ("noise") about the estimated parameters values. Also, studying a limited population sample introduces an element 
of randomness when attempting to extrapolate the results to the whole population. Finally, our inability to describe or model precisely a system may result from our lack of understanding and simplifications or misspecifications of the fitted models translate into parametric uncertainty (Bois 2001; Bois and Diack 2005). While variability is by essence irreducible and unavoidable, since it is a state of Nature, uncertainty can be reduced by new experiments, or by a better understanding of the biology and better models. In a further twist, the fact that uncertainty is almost always present hampers a precise assessment of variability. Statistical "population" models are able to disentangle partly uncertainty from variability. These models will be reviewed in section 7, below.

\section{A PRIORI PREDICTION OF VARIABILITY USING PBPK MODELING}

Predictive variability assessment with PBPK models proceeds nowadays with a combination of mechanism and data based refinements of the model structure (e.g., using age-dependent compartment volumes) (Clewell et al. 2004; Luecke et al. 2008) and stochastic modelling of the remaining random components of inter-individual differences. Numerical Monte Carlo methods (Clewell et al. 1999; Price et al. 2003; Spear et al. 1991; Woodruff et al. 1992), eventually hierarchical (Bois 1999; Bois et al. 1996a; Bois et al. 1996b), are the most widely used for the latter task. Those are best suited for complex models with many parameters. The basic assumption made by Monte Carlo simulations is that the randomness of the model state variables (e.g., blood concentration) is simply due to the randomness in the model parameter values. It is then enough to define statistical distributions for the parameters supposed to vary randomly in the population, and to sample the model parameter values from those distributions. The model is then run with the needed inputs and its outputs of interest are recorded. That sampling-running step constitutes a basic Monte Carlo iteration. As many iterations as needed can be performed to 
characterise precisely the statistical distribution of the recorded outputs. Additional details on Monte Carlo methods can be found in Ripley (1987).

Early attempts to use Monte Carlo methods and to simulate pharmacokinetic behaviour in "virtual populations" date back to the mid-1980s. Jackson et al. assessed the robustness of different experimental in vivo indices to detect and display genetic polymorphisms in human drugmetabolising activity (Jackson and Tucker 1990; Jackson et al. 1986). Monte Carlo analyses of PBPK models were also described at that time (Bois et al. 1990; Portier and Kaplan 1989). These simulations were later expanded to show the effect of variability in absorption, distribution, metabolism and excretion (ADME) parameters on the power of single time point estimates for the assessment of metabolic activity (Jackson et al. 1991), power analyses of bioequivalence measures (Bois et al. 1994a, b), the differentiation of parent drug and metabolite data in bioequivalence assessment (Rostami-Hodjegan et al. 1994), the discriminatory power of different indices of in vivo enzyme activity and the optimisation of sampling to assess such activity (Rostami-Hodjegan et al. 1996). Coupled with Monte Carlo methods, PBPK modelling has been used to assess the quantitative impact of physiological and environmental factors on human variability in toxicokinetics and pharmacokinetics in other publications (Bois et al. 1991; Clewell and Andersen 1996; Jamei et al. 2009a; Nestorov 2001; Sato 1991).

\section{SOURCES OF VARIABILITY IN PHARMACOKINETICS}

The overall inter-individual variability in pharmacokinetics can be simulated by considering the variability in key system parameters in PBPK modelling (Jamei et al. 2009a) (see Figure 2 for examples of clearance covariates). Details on the prediction of inter-individual variability in pharmacokinetics are discussed in detail below. 


\subsection{ABSORPTION}

There are many routes for xenobiotics to enter into the body which can generally be divided into topical, enteral and parenteral categories. Some of these routes (oral, infusion, intravenous, intramuscular, transdermal and inhalation) are routinely used to administrate drugs. The oral, transdermal and inhalation routes, which are most relevant to environmental exposures, are briefly discussed in this section.

Oral administration is the most common and convenient route of drug administration. Yet, it is often associated with low bioavailability and high inter-individual variability. Oral bioavailability $\left(F_{\text {oral }}\right)$ is defined as:

$$
F_{\text {oral }}=f_{a} \cdot F_{G} \cdot F_{H}
$$

where $f_{a}$ is the net fraction of dose absorbed from the intestinal tract, $F_{G}$ is the fraction of dose that escapes intestinal first-pass metabolism in the enterocytes, and $F_{H}$ is the fraction of dose that escapes hepatic first-pass metabolism. $f_{a}$ is discussed in this section and $F_{G}$ and $F_{H}$ will be discussed later.

Various factors can affect oral drug absorption. They can be divided into two categories: system (physiological and biological) factors and drug-related (physicochemical and pharmaceutical) factors. These factors can all contribute to the overall rate and extent of absorption, but mainly the system factors determine the inter-individual variability in absorption.

\subsubsection{Oral Absorption}

Key physiochemical properties, such as solubility and permeability are used in empirical methods to estimate the absorption potential of a drug (Artursson and Karlsson 1991; Dressman et al. 1985). Physiological models, such as the CAT model, have been developed to simulate mechanistically drug absorption (Yu and Amidon 1999). The CAT model has been further 
developed into the ACAT (Agoram et al. 2001) and the ADAM (Jamei et al. 2009b) models, which are respectively implemented within software Gastroplus (Simulation Plus Inc, California, USA, http://www.simulationsplus.com) and Simcyp Population-based ADME Simulator (Simcyp Ltd, Sheffield, UK, http://www.simcyp.com). In brief, these absorption models consist of physiologically based compartments corresponding to different segments of the gastrointestinal tract.

\section{Gastric Emptying Time}

The residence time of a drug in the stomach is an important factor determining the initiation of oral drug absorption. Variability in gastric emptying rates results in variable absorption rates and sometimes even variable absorption extents.

\section{Intestinal Residence Time}

Intestinal residence time can greatly affect oral drug absorption; particularly for drugs with low permeability. $\mathrm{Yu}$ and co-workers analyzed published data for low intestinal residence time in over 400 subjects and reported a mean value of 199 min with ranges of about 1 and 6 hours (Yu et al. 1996). Intestinal residence time appears to be relatively less dependent upon the nature of the dosage form (liquid $v s$. solid) than gastric residence time (Davis et al. 1986). The presence of food appears not to influence intestinal transit (Davis et al. 1986; Fadda et al. 2009).

\section{Gastrointestinal $\mathrm{pH}$}

The regional $\mathrm{pH}$ in the gastrointestinal tract can influence drug solubility and hence the dissolution of solid dosage forms. Gastrointestinal $\mathrm{pH}$ may also affect drug permeability by influencing the balance between ionised and non-ionised moieties. Fallingborg and co-workers measured $\mathrm{pH}$ profiles along the gastrointestinal tract in 39 healthy volunteers and observed a 
range of values up to two $\mathrm{pH}$ units at the same site in different subjects (Fallingborg et al. 1989). In addition, the presence of food in the gastrointestinal tract can raise the $\mathrm{pH}$ in the stomach and the proximal part of the small intestine, due to the buffering capacity of proteins.

\section{Transporters}

Various transporters are expressed in the apical and basolateral membranes of intestinal epithelial cells (Hilgendorf et al. 2007; Koepsell 1998; Koepsell et al. 2007; Murakami and Takano 2008; Tsuji and Tamai 1996). Much attention has been given to the efflux transporters (e.g., P-gp, MDR1 (ABCB1), MRP2 (ABCC2) and BCRP (ABCG2)) at the apical (brushborder) membrane of the intestine, as they can limit the intestinal absorption of drugs administered orally. Von Richter et al. (2004) measured P-gp in the human small intestine and reported a marked inter-individual variation in the intestinal P-gp expression. Additional data were reported by several later publications (Canaparo et al. 2007; Mouly and Paine 2003). Available data demonstrate that the expression levels of transporters vary along the gastrointestinal tract. Mouly and Paine (2003) found that relative P-gp levels increase progressively from the proximal to distal region of the small intestine. Other intestinal transporters may or may not follow the same pattern.

\subsubsection{Inhalation}

The large absorptive surface area, limited metabolic enzyme activity and active transporters in the pulmonary system make inhalation a favourable delivery strategy for systemic drugs with low bioavailability. In addition, many chemicals present in the air can get into body via the respiratory system. As for other routes of administration, the absorption kinetics in the lung tissues depend on both drug and system related parameters. Although inhalation is an established delivery strategy, the relationship between drug physicochemical properties and drug absorption kinetics in the lung has not been extensively investigated. In contrast to oral drug absorption 
little attention has been devoted to the question of how to optimize local drug absorption and retention in the lung (Yu and Rosania 2010). The state of the art on this question is somewhat more advanced for occupational exposures to volatile substances (Johanson 1990; Löf and Johanson 1998). Different aspects of lung physiology and formulation composition that influence the systemic delivery of inhaled therapeutics and recent advancement in inhaled drug delivery are reviewed in Patton and Byron (2007).

\subsubsection{Dermal Absorption}

The skin, the largest interface between the body and the environment, protects our body against chemical, physical, and microbial injury, loss of water, and other endogenous substances. It is also involved in the thermoregulation of the body and serves as an excretory organ (Schaefer et al. 2008). Understanding skin absorption processes enables us to assess the safety aspects of chemicals, xenobiotics, and cosmetic formulations as well as optimally utilizing dermal drug delivery. Permeation of drug molecules across the skin occurs by passive diffusion according to the activity gradient (Cleek and Bunge 1993; Krüse et al. 2007; McCarley and Bunge 2001; Potts and Guy 1992). The outer skin layer, stratum corneum, forms a rate-controlling barrier for diffusion of most compounds. The predominant diffusional path for a molecule crossing the stratum corneum appears to be intercellular (Hadgraft and Guty 2002). However this path is not exclusive and probably most molecules will pass through the stratum corneum by a combination of intercellular lipid domains, transcellular route and via the appendages (hair follicles, etc.) (Farahmand and Maibach 2009b).

Farahmand et al. investigated dermato-pharmacokinetic parameters of 12 transdermal patches and concluded that the serum concentration profile for transdermal therapeutic systems was affected by the physiological parameters, drug absorption and elimination. Therefore, in order to understand the variability in serum concentration it is necessary to take into account variability of each process involved (Farahmand and Maibach 2009a). 


\subsection{DISTRIBUTION}

The distribution process refers to the reversible transfer of drug from one location to another within the body. Factors that determine the distribution pattern of a drug with time include delivery of drug to tissue by blood, ability to cross tissue membranes, binding within blood and tissues, partitioning into fat, and tissue uptake (Rowland and Tozer 1995). The traditional description of the volume of distribution at steady state $\left(V_{s s}\right)$ corresponds to the sum of the products of each tissue to plasma partition coefficient $\left(\mathrm{K}_{\mathrm{p}: \mathrm{t}}\right)$ and the respective tissue volume in addition to the plasma volume (Sawada et al. 1984):

$$
V_{s s}=V_{p}+V_{e} \times(E: P)+\sum V_{t} \times K_{p: t}
$$

where $V_{p}, V_{e}$ and $V_{t}$ are the volumes of plasma, erythrocyte and tissue, respectively, $E: P$ is erythrocyte-to-plasma coefficient. Physiological factors affecting drug distribution include tissue volumes, tissue composition, blood perfusion rates to the tissues, plasma protein concentrations, hematocrit, and the expression of transporter proteins. Drug-specific factors determining the distribution behaviour of a drug include its ionisation, ability to cross membranes, bind to plasma proteins, partition into red blood cells and fat, and its specific affinity to influx or efflux transporter proteins.

Direct determination of $\mathrm{K}_{\mathrm{p}: \mathrm{t}}$ usually involves intravenous constant infusions to animals followed by an extraction and quantification of drugs from tissue homogenates (Lin et al. 1982a, b; Sawada et al. 1984), which is costly and time consuming. It is, therefore, of interest to predict $K_{p: t}$ values without conducting in vivo animal studies.

Several mechanistic equations have been proposed to predict the tissue affinities of volatile organic compounds (Fiserova-Bergerova 1983; Fiserova-Bergerova and Diaz 1986; FiserovaBergerova et al. 1980). Poulin and co-workers also developed mechanistic equations to predict the affinity of drugs for various tissues and organs (Poulin et al. 2001; Poulin and Theil 2000) 
and subsequently $V_{s s}$ predictions (Poulin and Theil 2002a) using Eq. 2. The species-specific tissue composition parameters can be found in the literature and have been summarised by Poulin and Theil (2002b). Corrections on these equations were later made by Berezhkovskiy (2004). More recently, Rodgers and co-workers extended and improved these equations by considering drug ionisation and incorporating more details on drug distribution inside tissues (Rodgers et al. 2005; Rodgers and Rowland 2006). Briefly, those equations are based on the assumption that all drugs will dissolve in intra- and extracellular tissue water and partition into the neutral lipids and neutral phospholipids located within tissue cells.

\subsubsection{Tissue Volumes and Tissue Blood Flows}

Tissue volumes and blood flows are essential components of a PBPK model. Early publications reported representative physiological parameters values but did not indicate the biological variability associated with those data (Davies and Morris 1993; Williams and Leggett 1989). Inter-individual variability on tissue volumes and tissue blood flows has been reported by later publications (de la Grandmaison et al. 2001; Price et al. 2003).

\subsubsection{Tissue Composition}

Hematocrit refers to the percentage of total blood volume composed of red blood cells. It is influenced by factors including age, sex, seasonal influence, and habits of physical activity (Morse et al. 1947a; Morse et al. 1947b; Thirup 2003). Compared with men, women on average have lower hematocrit. Hematocrit ranges between $40 \%-54 \%$ in males and $38 \%-47 \%$ in females.

Drug protein binding is the reversible interaction of drugs with plasma proteins. The extent of protein binding is a function of drug and protein concentrations, the affinity constant for the drug-protein binding and the number of protein binding sites (Grandison and Boudinot 2000). 
The major drug binding proteins in plasma are: albumin, AAG and lipoproteins. Albumin levels are generally decreased with age, whereas AAG levels are not significantly affected by age.

\subsubsection{Transporters}

Numerous drug transporters are found on the membranes of various tissues. These transporters can influence drug distribution into the tissues, particularly for drugs with low passive permeability. There is now increasing evidence to suggest that transporters may affect the volumes of distribution of certain drugs (Grover and Benet 2009). For most drugs, however, transporters may not significantly influence the volume of distribution, but may still influence the local kinetics in certain tissues (e.g., brain, liver, etc) and cause pharmacological or toxicological consequences. Polymorphism has been identified in transporters, as reviewed by Ho and Kim (2005).

\subsection{METABOLISM}

Drug metabolism reactions are generally grouped into 2 phases. Phase I metabolism includes oxidation, reduction, hydrolysis and hydration reactions. Phase II reactions use an endogenous compound, such as glucuronic acid, glutathione, or sulphate, for conjugation to the drug or its phase I-derived metabolite to produce a more polar end product that can be more readily excreted in bile or urine.

Although drug metabolism can take place in many organs, the liver has been long-recognised as the major site of metabolism for most drugs. More recently, the role of gut metabolism in firstpass metabolism has been increasingly recognised. The intestinal tissue is endowed with phase I and II enzymes, although at lower levels than those for the liver (Pang 2003). Several CYP enzymes have been detected in the human small intestine, including CYP1A2, CYP2D6, CYP2E1, CYP2C8, CYP2C9, CYP2C19, CYP3A4, and CYP3A5 (Paine et al. 2006). Among 
them, CYP3A4 is the most prominent enzyme present in the human intestine (Paine et al. 2006; Paine et al. 1997).

\subsubsection{Hepatic Metabolism}

Rane et al. (1977) successfully predicted in vivo hepatic metabolic clearance in rats based on in vitro data obtained from rat liver microsomes, taking into consideration the hepatic blood flow rate and the unbound fraction in blood. Since then, significant progresses have been achieved on predicting human hepatic metabolic clearance from a variety of in vitro systems, such as human liver microsomes, recombinant enzymes, and hepatocytes (Galetin et al. 2004; Houston 1994; Howgate et al. 2006; Iwatsubo et al. 1997; Obach 1999; Riley et al. 2005).

The unbound total hepatic intrinsic clearance $\left(C L u_{i n t, H}\right)$ can be extrapolated from in vitro clearance determined in a variety of in vitro systems using scaling factors as described in Barter (2007) and according to the procedure described by Rostami-Hodjegan and Tucker (2007):

Recombinantly expressed enzymes:

$$
\mathrm{CLu}_{\mathrm{int, \textrm {H }}}=\left[\sum_{j=1}^{n}\left(\sum_{i=1}^{n} I S E F_{j i} \times \frac{V \max _{i}\left(r h E n z_{i}\right) \times E n z_{i} \text { abundance }}{K m_{i}\left(r h E n Z_{i}\right)}\right)\right] \times M P P G L \times \text { Liver }_{-} \text {weight }
$$

where there are $i$ metabolic pathways for each of $j$ enzymes; ' $r h$ ' indicates recombinantly expressed enzyme; Vmax is the maximum rate of metabolism by an individual enzyme; $\mathrm{Km}$ is the Michaelis constant; MPPGL is the amount of microsomal protein per gram of liver; and ISEF is a scaling factor that compensates for any difference in the activity per unit of enzyme between recombinant systems and hepatic enzymes (Proctor et al. 2004).

Human liver microsomes:

$$
\mathrm{CLu}_{\mathrm{int}, \mathrm{H}}=\mathrm{CLu}_{\mathrm{int}}(\text { per_mg_microsomes }) \times M P P G L \times \text { Liver_weight }
$$

Human hepatocytes: 


$$
\mathrm{CLu}_{\mathrm{int}, \mathrm{H}}=\mathrm{CLu}_{\mathrm{int}}(\text { per_millions_hepatocytes }) \times H P G L \times \text { Liver_weight }
$$

where HPGL refers to hepatocellularity (millions of hepatocytes per gram of liver).

$C L u_{i n t, H}$ is then combined with other determinants to obtain total hepatic intrinsic clearance, using a liver model. Several hepatic clearance models have been developed to quantify the effects of hepatic blood flow, fraction unbound in blood, and hepatic intrinsic clearance on hepatic clearance (Wilkinson 1987). Among these models the well-stirred model (Eqs. 6 and 7) has been widely used for its mathematical simplicity and practicality, as shown below:

$$
\begin{gathered}
C L_{H, B}=\frac{Q_{H, B} \cdot f u_{B} \cdot C L u_{\mathrm{int}, H}}{Q_{H, B}+f u_{B} \cdot C L u_{\mathrm{int}, H}} \\
F_{H}=\frac{Q_{H, B}}{Q_{H, B}+f u_{B} \cdot C L u_{\mathrm{int}, H}}
\end{gathered}
$$

where $C L_{H, B}$ is hepatic drug clearance based on whole blood drug concentration, $Q_{H, B}$ is hepatic blood flow, $f u_{B}$ is the free fraction of drug in blood.

As indicated by Eq. 6, inter-individual variability in $\mathrm{CL}_{\mathrm{H}, \mathrm{B}}$ is influenced by the variability in three key parameters: $Q_{H, B}, f u_{B}$ and $C L u_{i n t, H}$.

\subsubsection{Gut Metabolism}

An operational model has been developed to predict first-pass metabolism in the gut. The " $Q_{\text {Gut }}$ " model (Eq. 8) (Rostami-Hodjegan and Tucker 2002; Yang et al. 2007; Yang et al. 2001) retains the form of the "well-stirred" model but the flow term $\left(Q_{G u t}\right)$ is a hybrid of both permeability through the enterocyte membrane and villous blood flow.

$$
F_{G}=\frac{Q_{G u t}}{Q_{G u t}+f u_{G} \cdot C L u_{\text {int }, G}}
$$

where $F_{G}$ is intestinal availability (fraction of dose that escapes intestinal first-pass metabolism in the enterocytes), $f u_{G}$ is the fraction of drug unbound in the enterocyte and its value is close to 
1 in most cases (Yang et al. 2007), $C L u_{i n t, G}$ is the unbound total gut intrinsic clearance, and $Q_{G u t}$ is a hybrid of both permeability through the enterocyte membrane and villous blood flow:

$$
Q_{\text {Gut }}=\frac{Q_{\text {villi }} \cdot C L_{\text {perm }}}{Q_{\text {villi }}+C L_{\text {perm }}}
$$

where $C L_{\text {perm }}$ is a clearance term defining permeability through the enterocyte and $Q_{\text {villi }}$ is villous blood flow (Yang et al. 2007).

\subsection{EXCRETION}

Excretion is the irreversible loss of the chemically unchanged drug. For most drugs, excretion occurs predominantly via the kidneys. However, some drugs and their metabolites are extensively excreted via the bile. Drug excretion can also happen via saliva, sweat, breast milk, and lungs, although their contributions to overall drug elimination are often small.

\subsubsection{Renal Excretion}

The kidney is the major site of drug excretion. Net renal drug excretion is a combination of three processes - glomerular filtration, tubular secretion and tubular reabsorption, as described by Eq. 10. Glomerular filtration of a drug is a passive process that is dependent upon the unbound fraction of a drug in plasma $(f u)$ and renal blood flow available for filtration, as described by Eq. 11. Tubular secretion occurs predominantly in the proximal tubule, and is mediated by several families of transporters. Tubular reabsorption of a drug can be a passive or an active transport process. Passive reabsorption may occur throughout the nephron. Active reabsorption occurs in the proximal tubule and, similar to tubular secretion, is energy-dependent, saturable, stereospecific and also likely to be associated with competitive drug interactions (Tett et al. 2003).

$$
\text { Rate of Excretion }=(\text { Rate of Filtration }+ \text { Rate of Active Secretion })\left(1-F_{R}\right)
$$




$$
\text { Rate of Filtration }=f u \times G F R \times C
$$

where $F_{R}$ is the fraction of drug reabsorbed from tubule lumen; fu is the fraction unbound in plasma; GFR is the glomerular filtration rate; and $C$ is drug concentration in plasma.

The primary determinants of renal excretion include renal blood flow, plasma protein binding, urine flow, urine $\mathrm{pH}$, and renal transporters (Garrett 1978; Tucker 1981).

Renal transporters play key roles in the secretion and reabsorption of many drugs and can significantly contribute to the variability in renal excretion of these compounds (Lee and Kim 2004). Organic anion and organic cation transport systems are two major drug transport systems in the human kidney (Dresser et al. 2001), and the effects of genetic variations in transporters on renal clearance have been investigated recently (Wang et al. 2008).

\subsubsection{Biliary Excretion}

Biliary excretion is one of the primary elimination routes for xenobiotics and the conjugate metabolites (Arias et al. 1993). Biliary excretion requires active secretory transport because drugs are transported across the biliary epithelium against a concentration gradient. Often drugs excreted into the bile undergo some degree of reabsorption along the intestine (enterohepatic circulation).

Ghibellini and co-workers used in vitro data obtained from sandwich-cultured human hepatocytes to predict the biliary clearance for three drugs, and the predicted values were significantly lower than in vivo data (Ghibellini et al. 2007). Biliary excretion is mediated by transporters in the canalicular membrane. Therefore, genetic variation in these transporters contributes to the inter-individual variability in biliary excretion. Several recent reviews have summarised the key transporters involved in hepatobiliary disposition of drugs (Chandra and Brouwer 2004; Ghibellini et al. 2006). 


\subsection{CO-EXPOSURES}

Part of the variability in metabolism observed in humans may also be due to uncontrolled coexposures to naturally occurring food-borne substances, environmental contaminants, therapeutic drugs, or chemical substances in the workplace. Drug-drug interactions are a well-known problem falling under that umbrella (Jamei et al. 2009a; Rostami-Hodjegan and Tucker 2007), but its generalisation to many-substance exposure remains to be better explored. The necessary tools are becoming available under the auspices of systems biology (Bois 2010).

\section{EXAMPLES OF APPLICATION OF A PRIORI MODELLING TO CHEMICAL RISK ASSESSMENT}

Risk assessments are performed to estimate the conditions under which individuals or populations may be harmed by exposure to environmental or occupational chemicals. In the absence of quantitative data in the human, this process is often dependent upon the use of animal and in vitro data to estimate human response. To reduce the uncertainty inherent in such extrapolations, there has been considerable interest in the development of PBPK models of toxic chemicals for application in quantitative risk assessments. PBPK models are effective tools for integrating internal dose assessment with diverse dose-response and mechanistic data in order to more accurately predict human risk (Andersen et al. 1987). One of the more challenging issues that must be considered in performing a human health risk assessment is the heterogeneity among humans. This heterogeneity is produced by inter-individual variations in physiology, biochemistry, and molecular biology, reflecting both genetic and environmental factors, and results in differences among individuals in the biologically effective tissue dose associated with a given environmental exposure (pharmacokinetics) as well as in the response to a given tissue dose (pharmacodynamics). 
There has sometimes been a tendency in risk assessments to use information on the variability of a specific parameter, such as inhalation rate or the in vitro activity of a particular enzyme, as the basis for expectations regarding the variability in dosimetry for in vivo exposures. However, whether or not the variation in a particular physiological or biochemical parameter will have a significant impact on in vivo dosimetry is a complex function of interacting factors. In particular, the structures of physiological and biochemical systems frequently involve parallel processes (e.g., blood flows, metabolic pathways, excretion processes), leading to compensation for the variation in a single factor. Moreover, physiological constraints may limit the in vivo impact of variability observed in vitro (Johanson et al. 1999). For instance, high affinity intrinsic clearance can result in essentially complete metabolism of all the chemical reaching the liver in the blood; under these conditions, variability in amount metabolized in vivo would be more a function of variability in liver blood flow than variability in metabolism in vitro. Thus it is often true that the whole (the in vivo variability in dosimetry) is less than the sum of its part (the variability in each of the pharmacokinetic factors). Because the parameters in a PBPK model have a direct biological correspondence, they provide a useful framework for determining the impact of observed variations in physiological and biochemical factors on the population variability in dosimetry within the context of a risk assessment for a particular chemical (Clewell and Andersen 1996; Price et al. 2003).

It is important at this point to remember the distinction made above between uncertainty and variability. Early attempts to distinguish the contributions of uncertainty and variability can be found in Bogen and Spear (1987) or Allen et al. (1996). Several studies have attempted to estimate the impact of parameter variability in PBPK models on risk assessment predictions using the Monte Carlo approach (Allen et al. 1996; Clewell and Andersen 1996; Clewell et al. 1999; Clewell and Jarnot 1994). As will be discussed in the next section, the use of a hierarchical Bayesian approach and Markov chain Monte Carlo simulations makes it possible to refine prior estimates of parameter variability on the basis of experimental data. The hierarchical Bayesian 
approach is increasingly being used to characterize both the uncertainty and variability in PBPK model predictions (Bois 2000; Gelman et al. 1996; Hack et al. 2006; Jonsson et al. 2001b; Jonsson and Johanson 2001a; Qiu et al. 2010).

It is useful in that context to consider the total variability among humans in terms of three contributing sources: (1) the variation across a population of "normal" individuals at the same age, e.g., young adults; (2) the variation across the population resulting from their different ages, e.g., infants or the elderly; and (3) the variation resulting from the existence of subpopulations that differ in some way from the "normal" population, e.g., due to genetic polymorphisms. A fourth source of variability, health status, should also be considered, although it is frequently disregarded in environmental risk assessment. To the extent that the variation in physiological and biochemical parameters across these population dimensions can be elucidated, PBPK models can be used together with Monte Carlo methods to integrate their effects on the in vivo kinetics of a chemical exposure and predict the resulting impact on the distribution of risks (as represented by target tissue doses) across the population. The following examples illustrate the application of PBPK models to inform population variability of the three types described above.

\section{Example 1: Population Variability}

Acceptable exposures to environmental contaminants are typically defined using a single value, such as the USEPA's Reference Dose (RfD), which represents a daily ingestion rate considered to be without harm for most individuals. In the case of methylmercury, a PBPK model was used in a Monte Carlo analysis to provide information on the distribution of acceptable ingestion rates across the population (Clewell et al. 2000; Clewell et al. 1999). That is in contrast to the regulatory approach based on a single point estimate obtained using conservative assumptions. In that analysis, the maternal hair concentration associated with neurological effects in the offspring from an epidemiological study was converted to an expected distribution of daily ingestion rates across a population of U.S. women of childbearing age. The resulting distribution 
of acceptable daily ingestion rates (RfDs) ranged from approximately 0.3 to $1.1 \mu \mathrm{g} / \mathrm{kg} / \mathrm{day}$, with a population median (50th percentile) of $0.5 \mu \mathrm{g} / \mathrm{kg} / \mathrm{day}$. This population distribution was used to inform risk-benefit analysis for alternative risk management options for contaminated sediment. In essence, the question here was: "How conservative are default conservative assumptions?". The answer, given by Monte Carlo derived uncertainty and variability estimates, was in that case: "Very conservative".

\section{Example 2: Age-Dependent Variability}

The following example illustrates the use of PBPK modelling to investigate the impact of pharmacokinetic variability on risk for the case of age-dependent pharmacokinetics. Specifically, the question being evaluated in this example is how normal changes in pharmacokinetic parameters from birth, through childhood, and across adulthood affect the dosimetry for environmental exposures to chemicals. To this end, a previously developed PBPK model for isopropanol and its metabolite acetone (Clewell et al. 2001) was adapted to simulate the physiological and biochemical changes in humans associated with growth and aging. In the agedependent model, all physiological and biochemical parameters change with time based on data from the literature (Clewell et al. 2004).

Figure 3 shows the results of using this age-dependent model to simulate continuous inhalation of isopropanol at $1 \mathrm{ppb}$, beginning at birth and continuing for 75 years (Clewell et al. 2004). The model predicts that, for the same inhaled concentration, the blood concentrations achieved during early life are significantly higher than those achieved during adulthood. In the case of the metabolite acetone, however, it should be noted that production from isopropanol metabolism would be only a small fraction of endogenous production from ketogenesis. Obviously, these are only model predictions, but while waiting for a real-life epidemiological validation (which would be very costly and difficult to perform), they form a reasonable and transparent basis for immediate decision making. 


\section{Example 3: Genetic Polymorphism}

The next example demonstrates the use of PBPK modelling, together with Monte Carlo techniques, to evaluate the impact of a genetic polymorphism for metabolism. In the example described here, the polymorphism of interest is for the enzyme paraoxonase. The PBPK model used in the analysis (Gearhart et al. 1993) describes exposure to parathion, its metabolism to paraoxon, and the inhibition of acetylcholinesterase by paraoxon. Paraoxonase is one of the enzymes responsible for the metabolic clearance of paraoxon. In vitro data on the two human alleles of paraoxonase (low and high activity) were used to develop distributions for the metabolism parameters in the PBPK model (Gentry et al. 2002). Monte Carlo simulations were then performed to generate the resulting distribution of predicted blood concentrations of paraoxon across a population, considering the variability in other pharmacokinetic parameters. Figure 4 displays the predicted distribution for the time-integrated (area under the curve) blood concentrations of paraoxon (mg-hr/L) across the sensitive population (dark bars), as compared to the "normal" population, following exposure to parathion at a dose of $0.033 \mathrm{mg} / \mathrm{kg}$ (Gentry et al. 2002). The impact of genetic polymorphism is strongly dampened by rate-limiting pharmacokinetic effects, similarly to what was observed for methyl chloride (Johanson et al. 1999). The calculation performed here lead to internal dose levels very different from those which would be obtained using naive "all or nothing" guessed estimates based solely on qualitative genotype considerations.

\section{A POSTERIORI ESTIMATION OF VARIABILITY USING BAYESIAN PBPK MODELING}

Purely predictive modelling, as described above, can be cross-validated by confronting its predictions (e.g., for plasma concentration of a substance) to data obtained of a sample of individuals. In the ideal case, data and predictions agree on average and in terms of variability 
and no further model refinement is attempted. Yet, quite often, the predictions are less than "perfect" and may even be really poor (but publication bias reduces the visibility of that case). That may be the occasion to improve the model through some calibration or data integration procedure and learn something about the true determinants of variability in a population (Wakefield and Bennett 1996). However, some care should be taken to properly disentangle uncertainty from variability in that calibration process, while retaining the prior physiological knowledge afforded by PBPK modelling (Gelman et al. 1996). The "naive" approach consists in fitting individual subjects' data separately, collecting the resulting individual parameter estimates and forming their average etc. That approach does not work and is actually incorrect if very precise parameter estimates cannot be obtained from the data (Beal and Sheiner 1982; Smith and Wakefield 1994). For ethical, feasibility or cost reasons, the data on individuals tend to be sparse in clinical pharmacokinetics or toxicokinetics. Such data usually lead to fairly uncertain parameter estimates and the so-called population approaches should then be used (Beal and Sheiner 1980).

Population models, or multilevel models, were first introduced in the context of pharmacokinetic studies for drug development and evaluation (Sheiner 1984). Their objective is to obtain, from data on individuals, a quantitative description of the variability of the kinetics of a compound within a large population. The same structural (e.g., PBPK) model is used describe the data for each subject, and that the model parameters differ randomly between subjects (see Figure 5) (Bois et al. 1996a; Bois et al. 1996b). Such randomness characterises variability can be described by a multivariate probability distribution. In population models, information of each subject is reinforced by "borrowing strength" from the other subjects' data and the overall estimation process is improved. Individuals' metabolic clearance, for example, can be assumed to be lognormally distributed around a "population mean", with a "population variance" which measures variability in the population. The population means and variances (one for each kinetic parameter supposed to vary between subjects) are aptly named "population" parameters. They 
are estimated during the model calibration (data fitting) together with the parameters of each subject (Bois 2001).

A number of methods are available to calibrate population models (Beal and Sheiner 1982; Davidian and Gallant 1992; Mallet et al. 1988; Racine-Poon and Smith 1990). Bayesian approaches have emerged as the best suited for PBPK models, given the large amount of prior information they require (Bernillon and Bois 2000; Gelman et al. 1996). But as we have seen above, a large amount of that information is already encoded as prior distributions, and updating those distributions with system's level data, is simply a matter of using Bayesian numerical methods such as Markov chain Monte Carlo simulations (Gelman and Rubin 1996).

A number of applications of posterior Bayesian PBPK modelling have been published: on benzene (Bois et al. 1996b), butadiene (Mezzetti et al. 2003), carbaryl (Nong et al. 2008), chloroform (Lyons et al. 2008), dichloromethane (Bois 1999; David et al. 2006; Johanson et al. 1999; Jonsson et al. 2001b; Jonsson and Johanson 2001a, 2003; Marino et al. 2006; Marino and Starr 2007), methyl chloride (Jonsson et al. 2001a), methyl mercury (Allen et al. 2007), nanoparticles (Péry et al. 2009), tetrachloroethylene (Bois et al. 1996a; Chiu and Bois 2006; Covington et al. 2007), toluene (Jonsson and Johanson 2001b; Vicini et al. 1999), and trichloroethylene (Bois 2000). Extension to questions of optimal design (Bois et al. 1999), medical image analysis (Brochot et al. 2006), or exposure reconstruction (Allen et al. 2007) have also been proposed.

\section{CONCLUSIONS}

The state of the art on PBPK modelling of inter-individual variability has advanced to the point of being a mainstream commercial activity for drug development. We have shown how the concepts and tools now available (generic PBPK models, applicable to many substances, coupled to databases of parameter distributions and QSAR models; MCMC software routines for 
Bayesian data integration) can foster predictive toxicokinetics for environmental or occupational contaminants. Computation time is not an issue anymore, and the approach is being extended to toxicodynamics through the use of biology-motivated effect models, toward a true predictive toxicology applicable to very large number of chemicals.

\section{ACKNOWLEDGEMENTS}

FYB was supported by the European Commission, $7^{\text {th }}$ FP project PREDICT-IV [grant agreement \#202222] and the French Ministry for the Environment (PRG189_07_DRC03). MJ would like to thank the Simcyp team for its contributions to the development of the Simcyp ${ }^{\circledR}$ Populationbased Simulator and also appreciate the continued support of the Simcyp Consortium members and the support received from the PREDICT-IV project.

\section{REFERENCES}

Agoram, B., Woltosz, W.S. and Bolger, M.B. (2001) Predicting the impact of physiological and biochemical processes on oral drug bioavailability. Adv Drug Deliv Rev 50 (Suppl 1), S41S67.

Allen, B.C., Covington, T.R. and Clewell, H.J. (1996) Investigation of the impact of pharmacokinetic variability and uncertainty on risks predicted with a pharmacokinetic model for chloroform. Toxicology and Applied Pharmacology 111, 289-303.

Allen, B.C., Hack, C.E. and Clewell, H.J. (2007) Use of Markov chain Monte Carlo analysis with a physiologically-based pharmacokinetic model of methylmercury to estimate exposures in US women of childbearing age. Risk Analysis 27, 947-959.

Andersen, M.E. (1995) What do we mean by ... dose? Inhalation Toxicology 7, 909-915. 
Andersen, M.E., Clewell, H.J., III, Gargas, M.L., Smith, F.A. and Reitz, R.H. (1987) Physiologically based pharmacokinetics and the risk assessment process for methylene chloride. Toxicology and Applied Pharmacology 87, 185-205.

Andersen, M.E., Reddy, M.B., Clewell, H.J. and Yang, R.S. (2005) Conclusions and future directions. In: M.B. Reddy, R.S. Yang, M.E. Andersen and H.J. Clewell (Eds), Physiologically Based Pharmacokinetic Modeling : Science and Applications, John Wiley \& Sons, pp. 389399.

Arias, I.M., Che, M., Gatmaitan, Z., Leveille, C., Nishida, T. and St Pierre, M. (1993) The biology of the bile canaliculus, 1993. Hepatology 17, 318-329.

Artursson, P. and Karlsson, J. (1991) Correlation between oral drug absorption in humans and apparent drug permeability coefficients in human intestinal epithelial (Caco-2) cells. Biochem Biophys Res Commun 175, 880-885.

Barter, Z.E., Bayliss, M.K., Beaune, P.H., Boobis, A.R., Carlile, D.J., Edwards, R.J., Houston, J.B., Lake, B.G., Lipscomb, J.C., Pelkonen, O.R., Tucker, G.T. and Rostami-Hodjegan, A. (2007) Scaling factors for the extrapolation of in vivo metabolic drug clearance from in vitro data: reaching a consensus on values of human microsomal protein and hepatocellularity per gram of liver. Curr Drug Metab 8, 33-45.

Barton, H.A., Chiu, W.A., Setzer, W., Andersen, M.E., Bailer, A.J., Bois, F.Y., DeWoskin, R.S., Hays, S., Johanson, G., Jones, N., Loizou, G., MacPhail, R.C., Portier, C.J., Spendiff, M. and Tan, Y.-M. (2007) Characterizing uncertainty and variability in physiologically-based pharmacokinetic (PBPK) models: state of the science and needs for research and implementation. Toxicological Sciences 99, 395-402.

Beal, S.L. and Sheiner, L.B. (1980) The NONMEM system. American Statistician 34, 118-119. 
Beal, S.L. and Sheiner, L.B. (1982) Estimating population kinetics. CRC Critical Reviews in Biomedical Engineering 8, 195-222.

Berezhkovskiy, L.M. (2004) Volume of distribution at steady state for a linear pharmacokinetic system with peripheral elimination. J Pharm Sci 93, 1628-1640.

Bernillon, P. and Bois, F.Y. (2000) Statistical issues in toxicokinetic modeling: a Bayesian perspective. Environmental Health Perspectives 108 (suppl. 5), 883-893.

Bogen, K.T. and Spear, R.C. (1987) Integrating uncertainty and interindividual variability in environmental risk assessment. Risk Analysis 7, 427-436.

Bois, F.Y. (1999) Analysis of PBPK models for risk characterization. Annals of the New York Academy of Sciences 895, 317-337.

Bois, F.Y. (2000) Statistical analysis of Clewell et al. PBPK model of trichloroethylene kinetics. Environmental Health Perspectives 108 (suppl. 2), 307-316.

Bois, F.Y. (2001) Applications of population approaches in toxicology. Toxicology Letters 120, 385-394.

Bois, F.Y. (2010) Physiologically-based modelling and prediction of drug interactions. Basic and Clinical Pharmacology and Toxicology 106, 154-161.

Bois, F.Y. and Diack, C. (2005) Uncertainty Analysis: The Bayesian Approach. In: L. Edler and C.P. Kitsos (Eds), Quantitative Methods for Cancer and Human health Risk Assessment, Wiley, New-York.

Bois, F.Y., Gelman, A., Jiang, J., Maszle, D., Zeise, L. and Alexeef, G. (1996a) Population toxicokinetics of tetrachloroethylene. Archives of Toxicology 70, 347-355.

Bois, F.Y., Jackson, E.T., Pekari, K. and Smith, M.T. (1996b) Population toxicokinetic of benzene. Environmental Health Perspectives 104, 1405-1411. 
Bois, F.Y. and Paxman, D. (1992) An analysis of exposure rate effects for benzene using a physiologically based pharmacokinetic model. Regulatory Toxicology and Pharmacology 15, $122-136$

Bois, F.Y., Smith, T., Gelman, A., Chang, H.-Y. and Smith, A. (1999) Optimal design for a study of butadiene toxicokinetics in humans. Toxicological Sciences 49, 213-224.

Bois, F.Y., Tozer, T.N., Hauck, W.W., Chen, M.-L., Patnaik, R. and Williams, R.L. (1994a) Bioequivalence: performance of several measures of extent. Pharmaceutical Research 11, 715722.

Bois, F.Y., Tozer, T.N., Hauck, W.W., Chen, M.-L., Patnaik, R. and Williams, R.L. (1994b) Bioequivalence: performance of several measures of rate. Pharmaceutical Research 11, 966974.

Bois, F.Y., Woodruff, T.J. and Spear, R.C. (1991) Comparison of three physiologically-based pharmacokinetic models of benzene disposition. Toxicology and Applied Pharmacology 110, 79-88.

Bois, F.Y., Zeise, L. and Tozer, T.N. (1990) Precision and sensitivity analysis of pharmacokinetic models for cancer risk assessment: tetrachloroethylene in mice, rats and humans. Toxicology and Applied Pharmacology 102, 300-315.

Bouvier d'Yvoire, M., Prieto, P., Blaauboer, B.J., Bois, F.Y., Boobis, A., Brochot, C., Coecke, S., Freidig, A., Gundert-Remy, U., Hartung, T., Jacobs, M.N., Lavé, T., Leahy, D.E., Lennernäs, H., Loizou, G.D., Meek, B., C., P., Rowland, M., Spendiff, M., Yang, J. and Zeilmaker, M. (2007) Physiologically-based kinetic modelling (PBK modelling): meeting the 3Rs agenda - The report and recommendations of ECVAM Workshop 63a. Alternatives to Laboratory Animals 35, 661-671. 
Brochot, C., Bessoud, B., Balvay, D., Cuénod, C.-A., Siauve, N. and Bois, F.Y. (2006) Evaluation of antiangiogenic treatment effects on tumors microcirculation by Bayesian physiological pharmacokinetic modeling and magnetic resonance imaging. Magnetic Resonance Imaging 24, 1059-1067.

Canaparo, R., Finnstrom, N., Serpe, L., Nordmark, A., Muntoni, E., Eandi, M., Rane, A. and Zara, G.P. (2007) Expression of CYP3A isoforms and P-glycoprotein in human stomach, jejunum and ileum. Clin Exp Pharmacol Physiol 34, 1138-1144.

Chandra, P. and Brouwer, K.L. (2004) The complexities of hepatic drug transport: current knowledge and emerging concepts. Pharm Res 21, 719-735.

Chiu, W.A. and Bois, F.Y. (2006) Revisiting the population toxicokinetics of tetrachloroethylene. Archives of Toxicology 80, 386.

Cleek, R.L. and Bunge, A.L. (1993) A new method for estimating dermal absorption from chemical exposure. 1. General approach. Pharmaceutical Research 10, 497-506.

Clewell, H.J., 3rd and Andersen, M.E. (1996) Use of physiologically based pharmacokinetic modeling to investigate individual versus population risk. Toxicology 111, 315-329.

Clewell, H.J., Crump, K.S., Gentry, P.R. and Shipp, A.M. (2000) Site-specific reference dose for methylmercury for fish-eating populations. Fuel Processing Technology 65-66, 43-54.

Clewell, H.J., Gearhart, J.M., Gentry, P.R., Covington, T.R., VanLandingham, C.B., Crump, K.S. and Shipp, A.M. (1999) Evaluation of the uncertainty in an oral Reference Dose for methylmercury due to interindividual variability in pharmacokinetics. Risk Analysis 19, 547558.

Clewell, H.J., Gentry, P.R., Covington, T.R., Sarangapani, R. and Teeguarden, J.G. (2004) Evaluation of the potential impact of age- and gender-specific pharmacokinetic differences on tissue dosimetry. Toxicological Sciences 79, 381-393. 
Clewell, H.J., III, Gentry, P.R., Gearhart, J.M., Covington, T.R., Banton, M.I. and Andersen, M.E. (2001) Development of a physiologically based pharmacokinetic model of isopropanol and its metabolite acetone. Toxicological Sciences 63, 160-172.

Clewell, H.J. and Jarnot, B.M. (1994) Incorporation of pharmacokinetics in non-carcinogenic risk assessment: Example with chloropentafluorobenzene. Risk Analysis 14, 265-276.

Covington, T.R., Gentry, P.R., Van Landingham, C.B., Andersen, M.E., Kester, J.E. and Clewell, H.J. (2007) The use of Markov chain Monte Carlo uncertainty analysis to support a Public Health Goal for perchloroethylene. Regulatory Toxicology and Pharmacology 47, 1-18.

David, R.M., Clewell, H.J., Gentry, P.R., Covington, T.R., Morgott, D.A. and Marino, D.J. (2006) Revised assessment of cancer risk to dichloromethane II. Application of probabilistic methods to cancer risk determinations. Regulatory Toxicology and Pharmacology 45, 55-65.

Davidian, M. and Gallant, A.R. (1992) Smooth nonparametric maximum likelihood estimation for population pharmacokinetics, with application to quinidine. J Pharmacokinet Biopharm 20, 529-556.

Davies, B. and Morris, T. (1993) Physiological parameters in laboratory animals and humans. Pharm Res 10, 1093-1095.

Davis, S.S., Hardy, J.G. and Fara, J.W. (1986) Transit of pharmaceutical dosage forms through the small intestine. Gut 27, 886-892.

de la Grandmaison, G.L., Clairand, I. and Durigon, M. (2001) Organ weight in 684 adult autopsies: new tables for a Caucasoid population. Forensic Sci Int 119, 149-154.

Dresser, M.J., Leabman, M.K. and Giacomini, K.M. (2001) Transporters involved in the elimination of drugs in the kidney: organic anion transporters and organic cation transporters. J Pharm Sci 90, 397-421. 
Dressman, J.B., Amidon, G.L. and Fleisher, D. (1985) Absorption potential: estimating the fraction absorbed for orally administered compounds. J Pharm Sci 74, 588-589.

Edginton, A.N., Schmitt, W. and Willmann, S. (2006) Development and evaluation of a generic physiologically based pharmacokinetic model for children. Clinical Pharmacokinetics 45, 1013-1034.

Edginton, A.N., Theil, F.P., Schmitt, W. and Willmann, S. (2008) Whole body physiologicallybased pharmacokinetic models: their use in clinical drug development. Expert Opinion on Drug Metabolism \& Toxicology 4, 1143-1152.

Fadda, H., McConnell, E., Short, M. and Basit, A. (2009) Meal-Induced Acceleration of Tablet Transit Through the Human Small Intestine. Pharm Res 26, 356-360.

Fallingborg, J., Christensen, L.A., Ingeman-Nielsen, M., Jacobsen, B.A., Abildgaard, K. and Rasmussen, H.H. (1989) pH-profile and regional transit times of the normal gut measured by a radiotelemetry device. Aliment Pharmacol Ther 3, 605-613.

Farahmand, S. and Maibach, H.I. (2009a) Estimating skin sermeability from physicochemical characteristics of drugs: a comparison between conventional models and an in vivo-based approach. pp. 41-47.

Farahmand, S. and Maibach, H.I. (2009b) Transdermal drug pharmacokinetics in man: interindividual variability \& partial prediction. pp. 1-15.

Fiserova-Bergerova, V. (1983) Gases and their solubility: a review of fundamentals. In: F. Fiserova-Bergerova (Ed), Modeling of Inhalation Exposure to Vapors: Uptake, Distribution, and Elimination, CRC Press, Boca Raton, Florida, pp. 3-28.

Fiserova-Bergerova, V. and Diaz, M.L. (1986) Determination and prediction of tissue-gas partition coefficients. International Archives of Occupational and Environmental Health 58, 7587. 
Fiserova-Bergerova, V., Vlach, J. and Cassady, J.C. (1980) Predictable "individual differences" in uptake and excretion of gases and lipid soluble vapour - simulation study. British Journal of Industrial Medicine 37, 42-49.

Galetin, A., Brown, C., Hallifax, D., Ito, K. and Houston, J.B. (2004) Utility of recombinant enzyme kinetics in prediction of human clearance: impact of variability, CYP3A5, and CYP2C19 on CYP3A4 probe substrates. Drug Metab Dispos 32, 1411-1420.

Garrett, E.R. (1978) Pharmacokinetics and clearances related to renal processes. Int J Clin Pharmacol Biopharm 16, 155-172.

Gearhart, J.M., Mahle, D.A., Greene, R.J., Seckel, C.S., Flemming, C.D., Fisher, J.W. and Clewell, H.J., III. (1993) Variability of physiologically based pharmacokinetic (PBPK) model parameters and their effects on PBPK model predictions in a risk assessment for perchloroethylene (PCE). Toxicology Letters 68, 131-144.

Gelman, A., Bois, F.Y. and Jiang, J. (1996) Physiological pharmacokinetic analysis using population modeling and informative prior distributions. Journal of the American Statistical Association 91, 1400-1412.

Gelman, A. and Rubin, D.B. (1996) Markov chain Monte Carlo methods in biostatistics. Stat Methods Med Res 5, 339-355.

Gentry, P.R., Hack, C.E., Haber, L., Maier, A. and Clewell, H.J. (2002) An approach for the quantitative consideration of genetic polymorphism data in chemical risk assessment: examples with warfarin and parathion. Toxicological Sciences, 120-139.

Gerlowski, L.E. and Jain, R.K. (1983) Physiologically based pharmacokinetic modeling: principles and applications. J Pharm Sci 72, 1103-1127.

Ghibellini, G., Leslie, E.M. and Brouwer, K.L. (2006) Methods to evaluate biliary excretion of drugs in humans: an updated review. Mol Pharm 3, 198-211. 
Ghibellini, G., Vasist, L.S., Leslie, E.M., Heizer, W.D., Kowalsky, R.J., Calvo, B.F. and Brouwer, K.L. (2007) In vitro-in vivo correlation of hepatobiliary drug clearance in humans. Clin Pharmacol Ther 81, 406-413.

Gibaldi, M. and Perrier, D. (1982) Pharmacokinetics, Marcel Dekker, New York.

Grandison, M.K. and Boudinot, F.D. (2000) Age-related changes in protein binding of drugs: implications for therapy. Clin Pharmacokinet 38, 271-290.

Grover, A. and Benet, L. (2009) Effects of Drug Transporters on Volume of Distribution. The AAPS Journal 11, 250-261.

Hack, C.E., Chiu, W.A., Zhao, Q.J. and Clewell, H.J. (2006) Bayesian population analysis of a harmonized physiologically based pharmacokinetic model of trichloroethylene and its metabolites. Regulatory Toxicology and Pharmacology 46, 63-83.

Hadgraft, J. and Guty, R.H. (2002) Feasibility assessment in topical and transdermal delivery: mathematical models and in vitro studies. In: J. Hadgraft and R.H. Guty (Eds), Transdermal Drug Delivery, Informa Health Care, New York, pp. 1-25.

Hilgendorf, C., Ahlin, G., Seithel, A., Artursson, P., Ungell, A.L. and Karlsson, J. (2007) Expression of thirty-six drug transporter genes in human intestine, liver, kidney, and organotypic cell lines. Drug Metab Dispos 35, 1333-1340.

Ho, R.H. and Kim, R.B. (2005) Transporters and drug therapy: implications for drug disposition and disease. Clin Pharmacol Ther 78, 260-277.

Houston, J.B. (1994) Utility of in vitro drug metabolism data in predicting in vivo metabolic clearance. Biochem Pharmacol 47, 1469-1479.

Howgate, E.M., Rowland Yeo, K., Proctor, N.J., Tucker, G.T. and Rostami-Hodjegan, A. (2006) Prediction of in vivo drug clearance from in vitro data. I: impact of inter-individual variability. Xenobiotica 36, 473-497. 
Iwatsubo, T., Suzuki, H. and Sugiyama, Y. (1997) Prediction of species differences (rats, dogs, humans) in the in vivo metabolic clearance of YM796 by the liver from in vitro data. J Pharmacol Exp Ther 283, 462-469.

Jackson, P.R. and Tucker, G.T. (1990) Pharmacokinetic-pharmacogenetic modelling in the detection of polymorphisms in xenobiotic metabolism. Annals of Occupational Hygiene 34, 653-662.

Jackson, P.R., Tucker, G.T., Lennard, M.S. and Woods, H.F. (1986) Polymorphic drug oxidation: pharmacokinetic basis and comparison of experimental indices. Br J Clin Pharmacol $22,541-550$.

Jackson, P.R., Tucker, G.T. and Woods, H.F. (1991) Backtracking booze with Bayes--the retrospective interpretation of blood alcohol data. Br J Clin Pharmacol 31, 55-63.

Jamei, M., Dickinson, G.L. and Rostami-Hodjegan, A. (2009a) A framework for assessing interindividual variability in pharmacokinetics using virtual human populations and integrating general knowledge of physical chemistry, biology, anatomy, physiology and genetics: a tale of 'bottom-up' vs 'top-down' recognition of covariates. Drug Metabolism and Pharmacokinetics $24,53-75$.

Jamei, M., Turner, D., Yang, J., Neuhoff, S., Polak, S., Rostami-Hodjegan, A. and Tucker, G. (2009b) Population-based mechanistic prediction of oral drug absorption. The AAPS Journal 11, 225-237.

Johanson, G. (1990) Modelling of respiratory exchange of polar solvents. Annals of Occupational Hygiene 35, 323-339.

Johanson, G., Jonsson, F. and Bois, F.Y. (1999) Development of new technique for risk assessment using physiologically based toxicokinetic models. American Journal of Industrial Medicine suppl. 1, 101-103. 
Jonsson, F., Bois, F.Y. and Johanson, G. (2001a) Assessing the reliability of PBPK models using data from methyl chloride-exposed, non-conjugating human subjects. Archives of Toxicology $75,189-199$.

Jonsson, F., Bois, F.Y. and Johanson, G. (2001b) Physiologically based pharmacokinetic modeling of inhalation exposure of humans to dichloromethane during moderate to heavy exercise. Toxicological Sciences 59, 209-218.

Jonsson, F. and Johanson, G. (2001a) A Bayesian analysis of the influence of GSTT1 polymorphism on the cancer risk estimate for dichloromethane. Toxicology and Applied Pharmacology 174, 99-112.

Jonsson, F. and Johanson, G. (2001b) Bayesian estimation of variability in adipose tissue blood flow in man by physiologically based pharmacokinetic modeling of inhalation exposure to toluene. Toxicology 157, 177-193.

Jonsson, F. and Johanson, G. (2003) The Bayesian population approach to physiological toxicokinetic-toxicodynamic models - An example using the MCSim software. Toxicology Letters 138, 143-150.

Koepsell, H. (1998) Organic cation transporters in intestine, kidney, liver, and brain. Annu Rev Physiol 60, 243-266.

Koepsell, H., Lips, K. and Volk, C. (2007) Polyspecific organic cation transporters: structure, function, physiological roles, and biopharmaceutical implications. Pharm Res 24, 1227-1251.

Krüse, J., Golden, D., Wilkinson, S., Williams, F., Kezic, S. and Corish, J. (2007) Analysis, interpretation, and extrapolation of dermal permeation data using diffusion-based mathematical models. Journal of Pharmaceutical Sciences 96, 682-703.

Lee, W. and Kim, R.B. (2004) Transporters and renal drug elimination. Annu Rev Pharmacol Toxicol 44, 137-166. 
Lin, J.H., Sugiyama, Y., Awazu, S. and Hanano, M. (1982a) In vitro and in vivo evaluation of the tissue-to-blood partition coefficient for physiological pharmacokinetic models. J Pharmacokinet Biopharm 10, 637-647.

Lin, J.H., Sugiyama, Y., Awazu, S. and Hanano, M. (1982b) Physiological pharmacokinetics of ethoxybenzamide based on biochemical data obtained in vitro as well as on physiological data. J Pharmacokinet Biopharm 10, 649-661.

Löf, A. and Johanson, G. (1998) Toxicokinetics of organic solvents: a review of modifying factors. Critical Reviews In Toxicology 28, 571-650.

Loizou, G., Spendiff, M., Barton, H.A., Bessems, J., Bois, F.Y., Bouvier d'Yvoire, M., Buist, H., Clewell, H.J.I., B., M., Gundert-Remy, U., Goerlitz, G. and Schmitt, W. (2008) Development of good modelling practice for physiologically based pharmacokinetic models for use in risk assessment: the first steps. Regulatory Toxicology and Pharmacology 50, 400-411.

Luecke, R.H., Pearce, B.A., Wosilait, W.D., Doerge, D.R., Slikker, W. and Young, J.F. (2008) Windows ${ }^{\circledR}$ based general PBPK/PD modeling software. Computers in Biology and Medicine $38,962-978$.

Lyons, M.A., Yang, R.S.H., Mayeno, A.N. and Reisfeld, B. (2008) Computational toxicology of chloroform: reverse dosimetry using Bayesian inference, Markov chain Monte Carlo simulation, and human biomonitoring data. Environmental Health Perspectives 116, 10401046.

Mallet, A., Mentre, F., Steimer, J.L. and Lokiec, F. (1988) Nonparametric maximum likelihood estimation for population pharmacokinetics, with application to cyclosporine. J Pharmacokinet Biopharm 16, 311-327. 
Marino, D.J., Clewell, H., Gentry, P., Covington, T., Hack, C., David, R. and Morgott, D. (2006) Revised assessment of cancer risk to dichloromethane: part I Bayesian PBPK and doseresponse modeling in mice. Regulatory Toxicology and Pharmacology 45, 44-54.

Marino, D.J. and Starr, T.B. (2007) Probabilistic dose-response modeling: case study using dichloromethane PBPK model results. Regulatory Toxicology and Pharmacology 49, 285-300.

McCarley, K.D. and Bunge, A.L. (2001) Pharmacokinetic models of dermal absorption. Journal of Pharmaceutical Sciences 90, 1699-1719.

Mezzetti, M., Ibrahim, J.G., Bois, F.Y., Ryan, L.M., Ngo, L. and Smith, T.J. (2003) A Bayesian compartmental model for the evaluation of 1,3-butadiene metabolism. Journal of the Royal Statistical Society Series C 52, 291-305.

Morse, M., Cassels, D.E. and Schlutz, F.W. (1947a) Blood volumes of normal children. Am J Physiol 151, 448-458.

Morse, M., Cassels, D.E. and Schultz, F.W. (1947b) Available and interstitial fluid volumes of normal children. Am J Physiol 151, 438-447.

Mouly, S. and Paine, M.F. (2003) P-glycoprotein increases from proximal to distal regions of human small intestine. Pharm Res 20, 1595-1599.

Murakami, T. and Takano, M. (2008) Intestinal efflux transporters and drug absorption. Expert Opin Drug Metab Toxicol 4, 923-939.

Nestorov, I. (2001) Modelling and simulation of variability and uncertainty in toxicokinetics and pharmacokinetics. Toxicol Lett 120, 411-420.

Nestorov, I. (2003) Whole body pharmacokinetic models. Clin Pharmacokinet 42, 883-908.

Nestorov, I. (2007) Whole-body physiologically based pharmacokinetic models. Expert Opin Drug Metab Toxicol 3, 235-249. 
Nong, A., Tan, Y.M., Krolski, M.E., Wang, J.S., Lunchick, C., Conolly, R.B. and Clewell, H.J. (2008) Bayesian calibration of a physiologically based pharmacokinetic/pharmacodynamic model of carbaryl cholinesterase inhibition. Journal of Toxicology and Environmental HealthPart a-Current Issues 71, 1363-1381.

Obach, R.S. (1999) Prediction of human clearance of twenty-nine drugs from hepatic microsomal intrinsic clearance data: An examination of in vitro half-life approach and nonspecific binding to microsomes. Drug Metab Dispos 27, 1350-1359.

Paine, M.F., Hart, H.L., Ludington, S.S., Haining, R.L., Rettie, A.E. and Zeldin, D.C. (2006) The human intestinal cytochrome P450 "Pie". Drug Metab Dispos 34, 880-886.

Paine, M.F., Khalighi, M., Fisher, J.M., Shen, D.D., Kunze, K.L., Marsh, C.L., Perkins, J.D. and Thummel, K.E. (1997) Characterization of interintestinal and intraintestinal variations in human CYP3A-dependent metabolism. J Pharmacol Exp Ther 283, 1552-1562.

Pang, K.S. (2003) Modeling of intestinal drug absorption: roles of transporters and metabolic enzymes (for the Gillette Review Series). Drug Metab Dispos 31, 1507-1519.

Parrott, N., Jones, H., Paquereau, N. and Lavé, T. (2005) Application of full physiological models for pharmaceutical drug candidate selection and extrapolation of pharmacokinetics to man. Basic and Clinical Pharmacology and Toxicology 96, 193-196.

Patton, J.S. and Byron, P.R. (2007) Inhaling medicines: delivering drugs to the body through the lungs. pp. 67-74.

Péry, A., Brochot, C., Hoet, P., Nemmar, A. and Bois, F.Y. (2009) Development of a physiologically-based kinetic model for 99m-Technetium labelled carbon nanoparticles inhaled by humans. Inhalation Toxicology 21, 1099-1107.

Portier, C.J. and Kaplan, N.L. (1989) Variability of safe dose estimates when using complicated models of the carcinogenic process. Fundamental and Applied Toxicology 13, 533-544. 
Potts, R.O. and Guy, R.H. (1992) Predicting Skin Permeability. Pharmaceutical Research 9, 663669.

Poulin, P., Schoenlein, K. and Theil, F.P. (2001) Prediction of adipose tissue: plasma partition coefficients for structurally unrelated drugs. J Pharm Sci 90, 436-447.

Poulin, P. and Theil, F.P. (2000) A priori prediction of tissue:plasma partition coefficients of drugs to facilitate the use of physiologically-based pharmacokinetic models in drug discovery. $\mathrm{J}$ Pharm Sci 89, 16-35.

Poulin, P. and Theil, F.P. (2002a) Prediction of pharmacokinetics prior to in vivo studies 1 . Mechanism-based prediction of volume of distribution. J Pharm Sci 91, 129-156.

Poulin, P. and Theil, F.P. (2002b) Prediction of pharmacokinetics prior to in vivo studies II. Generic physiologically based pharmacokinetic models of drug disposition. J Pharm Sci 91, 1358-1370.

Price, P.S., Conolly, R.B., Chaisson, C.F., Gross, E.A., Young, J.S., Mathis, E.T. and Tedder, D.R. (2003) Modeling interindividual variation in physiological factors used in PBPK models of humans. Crit Rev Toxicol 33, 469-503.

Proctor, N.J., Tucker, G.T. and Rostami-Hodjegan, A. (2004) Predicting drug clearance from recombinantly expressed CYPs: intersystem extrapolation factors. Xenobiotica 34, 151-178.

Qiu, J., Chien, Y.C., Bruckner, J.V. and Fisher, J.W. (2010) Bayesian analysis of a physiologically based pharmacokinetic model for perchloroethylene in humans. Journal of Toxicology and Environmental Health 73, 74-91.

Racine-Poon, A. and Smith, A.F.M. (1990) Population models. In: D.A. Berry (Ed), Statistical Methodology in the Pharmaceutical Sciences, Dekker, New York, pp. 139-162.

Rane, A., Wilkinson, G.R. and Shand, D.G. (1977) Prediction of hepatic extraction ratio from in vitro measurement of intrinsic clearance. J Pharmacol Exp Ther 200, 420-424. 
Riley, R.J., McGinnity, D.F. and Austin, R.P. (2005) A unified model for predicting human hepatic, metabolic clearance from in vitro intrinsic clearance data in hepatocytes and microsomes. Drug Metab Dispos 33, 1304-1311.

Ripley, B.D. (1987) Stochastic Simulation, John Wiley and Sons, New York.

Rodgers, T., Leahy, D. and Rowland, M. (2005) Physiologically based pharmacokinetic modeling 1: Predicting the tissue distribution of moderate-to-strong bases. J Pharm Sci 94, $1259-1276$.

Rodgers, T. and Rowland, M. (2006) Physiologically based pharmacokinetic modelling 2: predicting the tissue distribution of acids, very weak bases, neutrals and zwitterions. J Pharm Sci 95, 1238-1257.

Rostami-Hodjegan, A., Jackson, P.R. and Tucker, G.T. (1994) Sensitivity of indirect metrics for assessing "rate" in bioequivalence studies--moving the "goalposts" or changing the "game". J Pharm Sci 83, 1554-1557.

Rostami-Hodjegan, A., Nurminen, S., Jackson, P.R. and Tucker, G.T. (1996) Caffeine urinary metabolite ratios as markers of enzyme activity: a theoretical assessment. Pharmacogenetics 6, 121-149.

Rostami-Hodjegan, A. and Tucker, G.T. (2002) The effects of portal shunts on intestinal cytochrome P450 3A activity. Hepatology 35, 1549-1550.

Rostami-Hodjegan, A. and Tucker, G.T. (2007) Simulation and prediction of in vivo drug metabolism in human populations from in vitro data. Nature Reviews Drug Discovery 6, 140148.

Rowland, M., Balant, L. and Peck, C. (2004) Physiologically based pharmacokinetics in drug development and regulatory science: a workshop report (Georgetown University, Washington, DC, May 29-30, 2002). AAPS PharmSci 6, E6. 
Rowland, M. and Tozer, T.N. (1995) Clinical pharmacokinetics: concepts and applications, Williams \& Wilkins, Baltimore ; London.

Sato, A. (1991) The effect of environmental factors on the pharmacokinetic behaviour of organic solvent vapours. Ann Occup Hyg 35, 525-541.

Sawada, Y., Hanano, M., Sugiyama, Y., Harashima, H. and Iga, T. (1984) Prediction of the volumes of distribution of basic drugs in humans based on data from animals. J Pharmacokinet Biopharm 12, 587-596.

Schaefer, U.F., Hansen, S., Schneider, M., Contreras, J.L. and Lehr, C.-M. (2008) Models for skin absorption and skin toxicity testing. Drug Absorption Studies, pp. 3-33.

Sheiner, L.B. (1984) The population approach to pharmacokinetic data analysis: rationale and standard data analysis methods. Drug Metabolism Reviews 15, 153-171.

Smith, A.F.M. and Wakefield, J. (1994) The hierarchical Bayesian approach to population pharmacokinetic modelling. International Journal of Bio-Medical Computing 36, 35-42.

Spear, R.C., Bois, F.Y., Woodruff, T., Auslander, D., Parker, J. and Selvin, S. (1991) Modeling benzene pharmacokinetics across three sets of animal data: parametric sensitivity and risk implications. Risk Analysis 11, 641-654.

Tett, S.E., Kirkpatrick, C.M., Gross, A.S. and McLachlan, A.J. (2003) Principles and clinical application of assessing alterations in renal elimination pathways. Clin Pharmacokinet 42, $1193-1211$.

Thirup, P. (2003) Haematocrit: within-subject and seasonal variation. Sports Med 33, 231-243.

Tsuji, A. and Tamai, I. (1996) Carrier-mediated intestinal transport of drugs. Pharm Res 13, 963977.

Tucker, G.T. (1981) Measurement of the renal clearance of drugs. Br J Clin Pharmacol 12, 761770. 
Vicini, P., Pierce, C.H., Dills, R.L., Morgan, M.S. and Kalman, D.A. (1999) Individual prior information in a physiological model of $\mathrm{H}$ - 2(8)-toluene kinetics: an empirical Bayes estimation strategy. Risk Analysis 19, 1127-1134.

von Richter, O., Burk, O., Fromm, M.F., Thon, K.P., Eichelbaum, M. and Kivisto, K.T. (2004) Cytochrome P450 3A4 and P-glycoprotein expression in human small intestinal enterocytes and hepatocytes: a comparative analysis in paired tissue specimens. Clin Pharmacol Ther 75, 172-183.

Wakefield, J. and Bennett, J. (1996) The Bayesian modeling of covariates for population pharmacokinetic models. Journal of the American Statistical Association 91, 917-927.

Wang, Z.J., Yin, O.Q., Tomlinson, B. and Chow, M.S. (2008) OCT2 polymorphisms and in-vivo renal functional consequence: studies with metformin and cimetidine. Pharmacogenet Genomics 18, 637-645.

Wilkinson, G.R. (1987) Clearance approaches in pharmacology. Pharmacol Rev 39, 1-47.

Williams, L.R. and Leggett, R.W. (1989) Reference values for resting blood flow to organs of man. Clin Phys Physiol Meas 10, 187-217.

Willmann, S., Edginton, A.N., Kleine-Besten, M., Jantratid, E., Thelen, K. and Dressman, J.B. (2009) Whole-body physiologically-based pharmacokinetic population modelling of oral drug administration: inter-individual variability of cimetidine absorption. Journal of Pharmacy and Pharmacology 61, 891-899.

Willmann, S., Höhn, K., Edginton, A., Sevestre, M., Solodenko, J., Weiss, W., Lippert, J. and Schmitt, W. (2007) Development of a physiology-based whole-body population model for assessing the influence of individual variability on the pharmacokinetics of drugs. Journal of Pharmacokinetics and Pharmacodynamics 34, 401-431. 
Woodruff, T. and Bois, F.Y. (1993) Optimization issues in physiological toxicokinetic modeling - a case study with benzene. Toxicology Letters 69, 181-196.

Woodruff, T., Bois, F.Y., Auslander, D. and Spear, R. (1992) Structure and parametrization of toxicokinetic models: their impact on model predictions. Risk Analysis 12, 189-201.

Yang, J., Jamei, M., Yeo, K.R., Tucker, G.T. and Rostami-Hodjegan, A. (2007) Prediction of Intestinal First-Pass Drug Metabolism. Curr Drug Metab 8, 676-684.

Yang, J., Rostami-Hodjegan, A. and Tucker, G.T. (2001) Prediction of ketoconazole interaction with midazolam, alprazolam and triazolam: incorporating population variability. Blackwell Science Ltd, Dublin, Ireland, pp. 472P-473P.

Yu, J.-y. and Rosania, G. (2010) Cell-Based multiscale computational modeling of small molecule absorption and retention in the lungs. pp. 457-467.

Yu, L.X. and Amidon, G.L. (1999) A compartmental absorption and transit model for estimating oral drug absorption. Int J Pharm 186, 119-125.

Yu, L.X., Crison, J.R. and Amidon, G.L. (1996) Compartmental transit and dispersion model analysis of small intestinal transit flow in humans. Int J Pharm 140, 111-118. 


\section{FIGURE CAPTIONS}

Figure 1: Structure of a generic PBPK model of the mammalian body.

Figure 2: The inter-correlation of covariates affecting drug clearance.

Figure 3: Blood concentrations of isopropanol (IPA) and its metabolite acetone as a function of age for continuous inhalation exposure at $1 \mathrm{ppb}$.

Figure 4: Paraoxon AUC distribution for the sensitive population compared to the AUC distribution for the "normal" population for a parathion dose of $0.033 \mathrm{mg} / \mathrm{kg}$.

Figure 5: Graphical representation of a toxicokinetic population model. Unknown quantities are in circles, known quantities in squares. At the individual level, exposure (E), time (t) and specific parameters $(\theta)$ condition the data $(\mathbf{y})$. The structural PBPK model, $f$, links $\mathbf{E}, \mathbf{t}, \theta$ and $\mathbf{y}$. Individual parameter values are randomly distributed in the population with population means $\boldsymbol{\mu}$ and variances $\Sigma^{2}$. Residual errors (measurement errors, modelling errors etc.) are lumped in the variance term $\sigma^{2}$. 


\section{FIGURES}

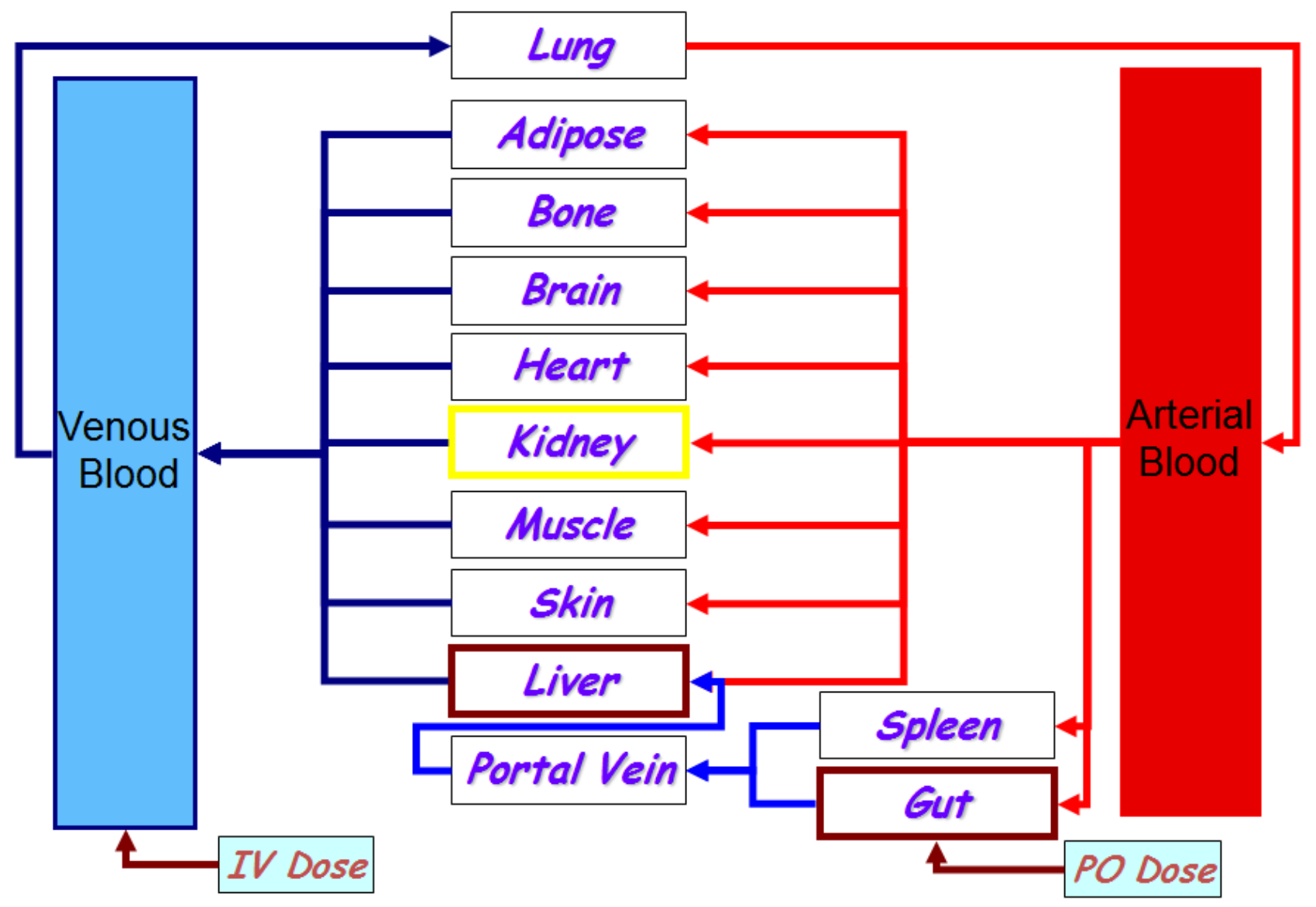

Figure 1: Structure of a generic PBPK model of the mammalian body. 


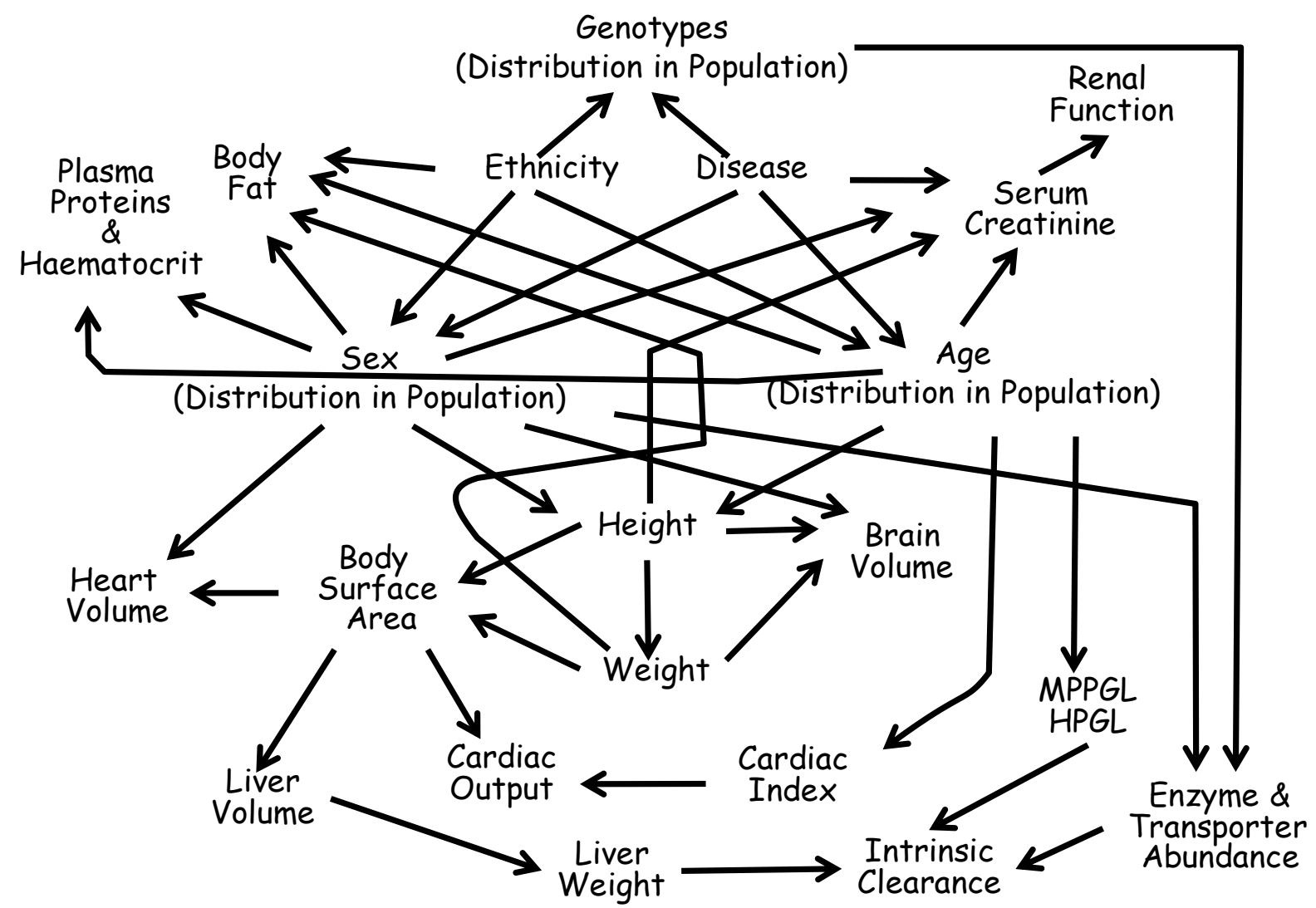

Figure 2: The inter-correlation of covariates affecting a chemical's clearance from the body, updated after (Jamei et al. 2009a). 


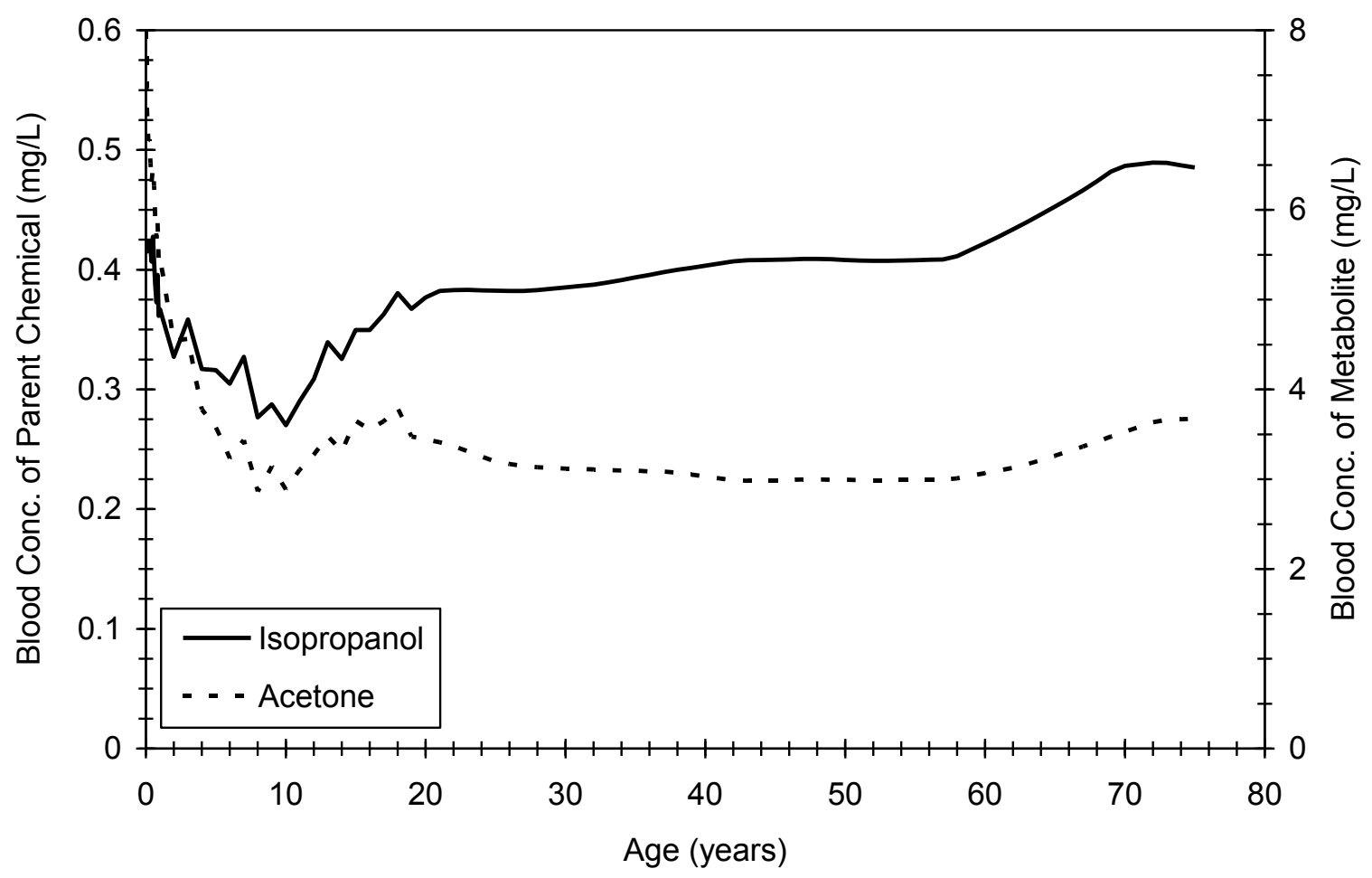

Figure 3: Blood concentrations of isopropanol (IPA) and its metabolite acetone as a function of age for continuous inhalation exposure at $1 \mathrm{ppb}$. 


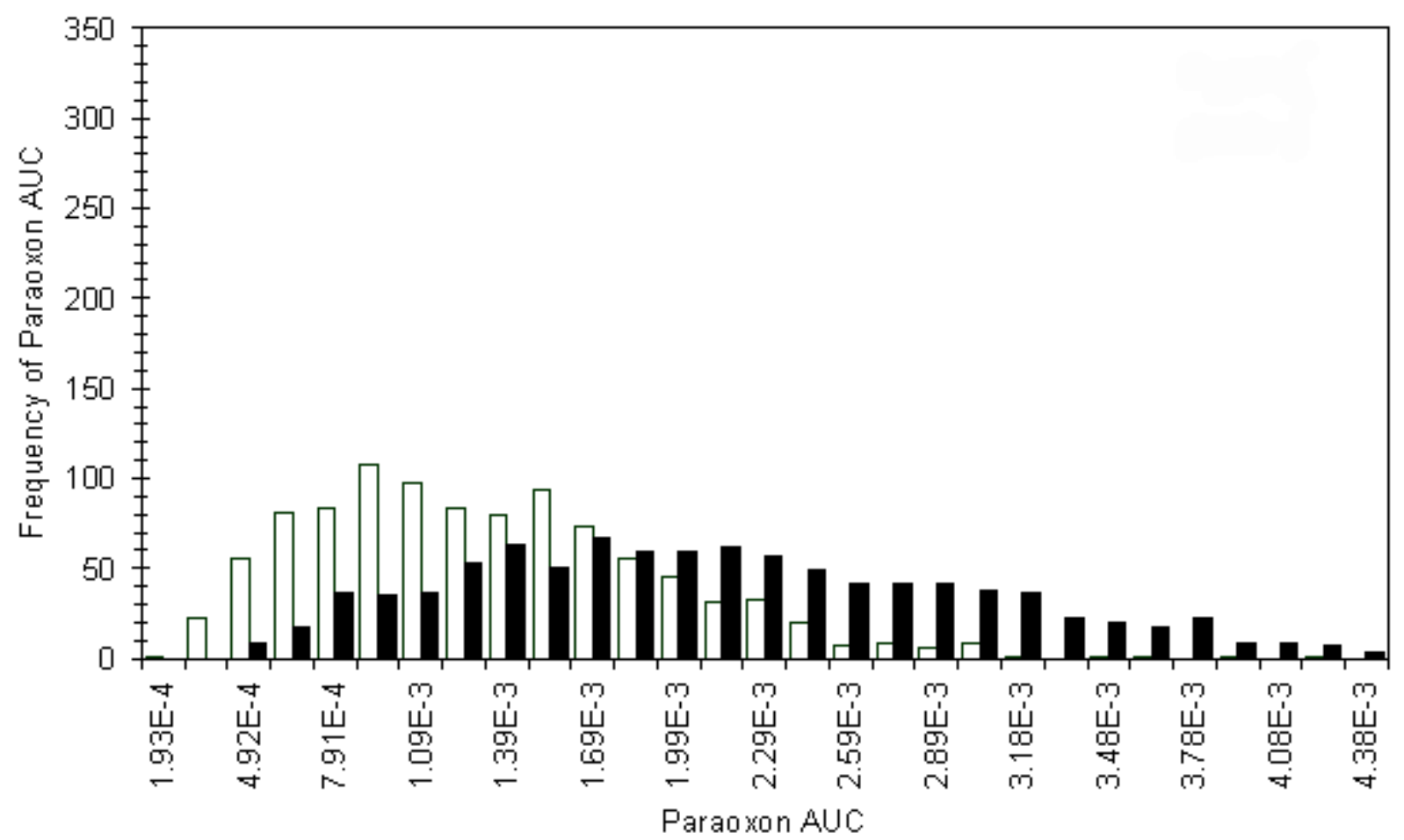

Figure 4: Paraoxon AUC distribution for the sensitive population (black bars) compared to the AUC distribution for the "normal" population (white bars) in for a parathion dose of 0.033 $\mathrm{mg} / \mathrm{kg}$. 


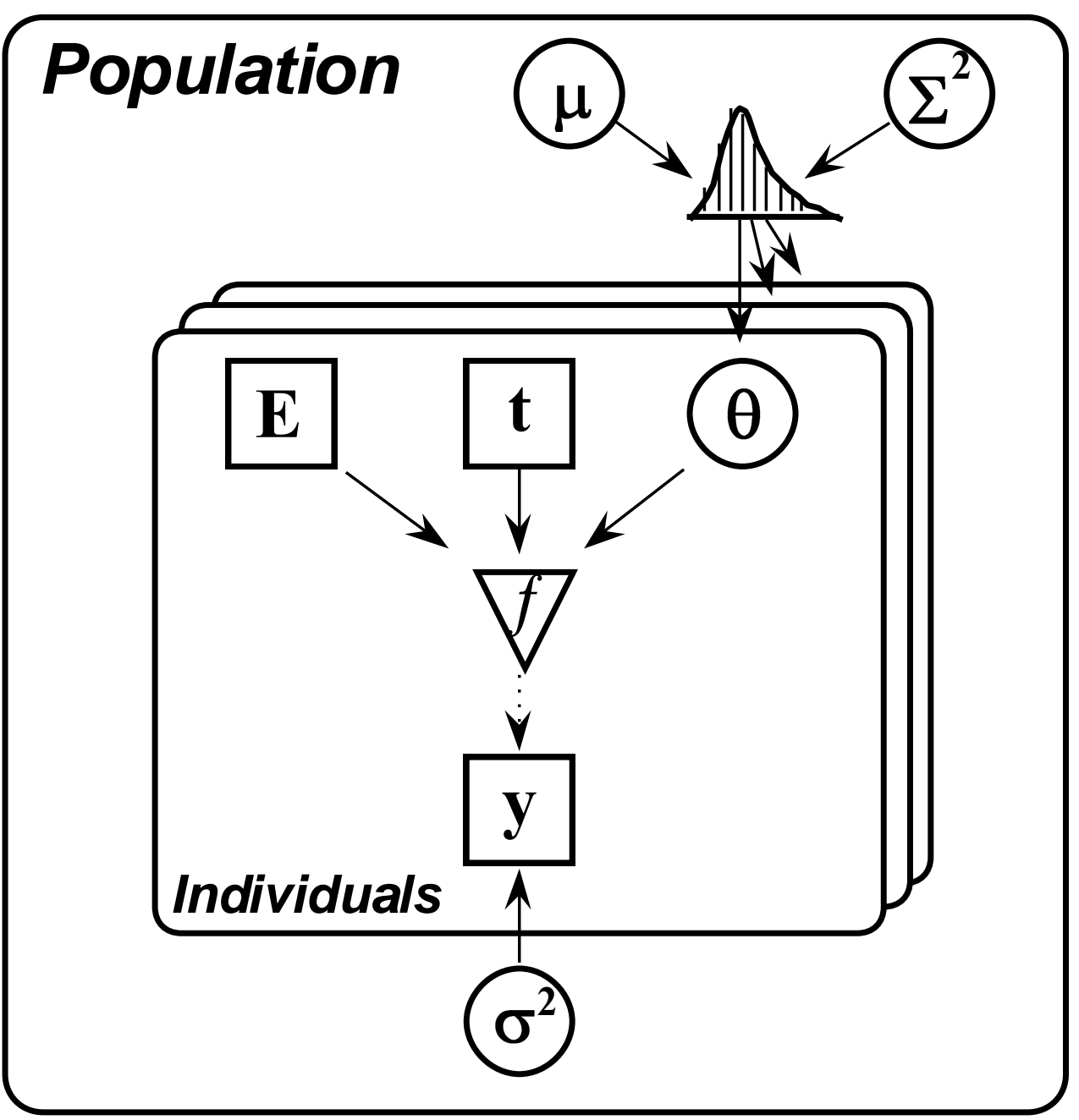

Figure 5: Graphical representation of a toxicokinetic population model. Unknown quantities are in circles, known quantities in squares. At the individual level, exposure (E), time $(\mathbf{t})$ and specific parameters $(\theta)$ condition the data $(\mathbf{y})$. The structural PBPK model, $f$, links $\mathbf{E}, \mathbf{t}, \theta$ and $\mathbf{y}$. Individual parameter values are randomly distributed in the population with population means $\boldsymbol{\mu}$ and variances $\sum^{2}$. Residual errors (measurement errors, modelling errors etc.) are lumped in the variance term $\sigma^{2}$. 